\title{
Laboreal
}

Volume $9 \mathrm{~N}^{\circ} 2$ | 2013

Varia

\section{Rol de la imagen operativa en la captura del contenido informacional de las señales}

Papel da imagem operativa na apreensão do conteúdo informacional dos sinais Rôle de l'image opérative dans la saisie du contenu informationnel des signaux. The role played by operative image in the apprehension of the informational content of signs

\section{Dimitri Ochanine}

Traductor. Bernardo Guagnini

\section{(2) OpenEdition}

Journals

Edición electrónica

URL: http://journals.openedition.org/laboreal/5844

DOI: $10.4000 /$ laboreal.5844

ISSN: 1646-5237

Editor

Universidade do Porto

Referencia electrónica

Dimitri Ochanine, «Rol de la imagen operativa en la captura del contenido informacional de las señales », Laboreal [En línea], Volume 9 №2 | 2013, Publicado el 01 diciembre 2013, consultado el 24 septiembre 2020. URL : http://journals.openedition.org/laboreal/5844 ; DOI : https://doi.org/10.4000/ laboreal.5844

Este documento fue generado automáticamente el 24 septiembre 2020.

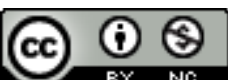

Laboreal está licenciado com uma Licença Creative Commons - Atribuição-NãoComercial 4.0 Internacional. 


\section{Rol de la imagen operativa en la captura del contenido informacional de las señales}

Papel da imagem operativa na apreensão do conteúdo informacional dos sinais Rôle de l'image opérative dans la saisie du contenu informationnel des signaux. The role played by operative image in the apprehension of the informational content of signs

Dimitri Ochanine

Tradución : Bernardo Guagnini

\section{REFERENCIA}

Artículo original: Ochanine, D. (1969). Rôle de l'image opérative dans la saisie du contenu informationnel des signaux. Questions de psychologie, $n^{\circ} 4,209-224$.

\section{Exposición del problema}

1 La acción sobre un objeto puede ser definida como un proceso en el cual se transforma la información sobre los estados sucesivos del objeto, en acciones realizadas sobre este objeto. Esta transformación tiene lugar luego de una confrontación de la información procedente del objeto con aquella que el sujeto ya posee, por ejemplo la información acerca de la forma o la estructura del objeto, su estado deseado, el algoritmo de su funcionamiento en tanto sistema dinámico, etc. Esta información preexistente, con la cual se confronta la información exteroceptiva, muy a menudo se presenta organizada en una imagen operativa.

2 Así pues, la imagen operativa siempre representa cierta información inmediatamente disponible acerca del objeto (información inherente a la imagen) reflejada en la 
consciencia del sujeto y que interactúa activamente con la información-señal, es decir con la información que le llega del exterior al sujeto en el transcurso de la acción. En primera instancia, la imagen operativa está caracterizada por su ordenamiento estructural: de una $u$ otra manera, la información proporcionada por la imagen operativa está estructurada en un todo coherente cuyos componentes se inscriben en un conjunto de relaciones determinado.

3 En el sistema psicológico funcional subyacente (cf. /1/, las imágenes operativas se alinean en un orden que depende de la función que tengan en la transformación de la información.

4 Nuestra intención acá es estudiar las imágenes operativas que permiten la aprehensión del contenido informacional de las señales. Como se sabe, el contenido de las señales puede ser tanto explícito como implícito, y en este último caso, es indispensable "un tratamiento complementario de la señal con el fin de desglosar la función informacional". Intentaremos demostrar que tal tratamiento se lleva a cabo gracias a imágenes operativas adecuadas. En una situación experimental, estas imágenes se forman inmediatamente antes de la acción, por medio de consignas verbales del experimentador, cuando el sujeto toma conocimiento de las condiciones de la experiencia.

5 En los casos aquí presentados, el tiempo de procesamiento no puede ser establecido de manera unívoca a partir de una cantidad abstracta de información proporcionada por las señales y calculada con la fórmula de Shannon o por cualquier otro medio. En la medida en que el tratamiento aquí se efectúa en el transcurso de la confrontación de las señales con la información contenida en la imagen, la complejidad y en consecuencia los tiempos de tratamiento deben ser determinados por la especificidad concreta de este proceso.

6 Obviando lo singular de cada circunstancia, la dificultad de este proceso de confrontación depende directamente de las particularidades de la imagen operativa en sí misma, a saber: 1) de la cantidad de información contenida en la imagen, la cual es indispensable tener en cuenta para tratar la señal (aspecto cuantitativo de la imagen); 2) de la estructura de la imagen, es decir la manera en que está organizada la información que contiene (aspecto cualitativo).

7 La importancia de las proposiciones formuladas más arriba es evidente. Si podemos imaginar una experiencia en la cual la imagen operativa del objeto nos es dada desde el comienzo o la podemos estimar - con una certeza considerable- a partir del comportamiento del sujeto, estaremos en posesión de un procedimiento experimental válido que nos permitirá apreciar la imagen operativa, es decir determinar su eficacia (su complejidad, su fiabilidad, etc.). Esto abriría las puertas a la formación acabada de imágenes operativas capaces de poner en evidencia, dentro de las posibilidades, el contenido informacional de las señales y de este modo facilitar la estrategia del tratamiento de la información-señal en la ejecución de tal o cual operación de trabajo.

Para esta investigación, proponemos concretamente las siguientes tareas:

$1^{\circ}$ Detectar el rol de la imagen operativa en la captura del contenido informacional de las señales.

$102^{\circ}$ Estudiar ciertas particularidades del proceso de formación de la imagen operativa para una clase de tareas delimitada por las condiciones de la experiencia, y mostrar su influencia sobre las dificultades de tratamiento de la información-señal. 


\section{Método de investigación}

Sobre una tabla vertical de $55 \times 65 \mathrm{~cm}$, se disponen 12 bombillas de señalización en forma de circunferencia. El diámetro de la circunferencia es de $30 \mathrm{~cm}$ y el ángulo que va desde el ojo del sujeto hasta dos bombillas opuestas cualesquiera que sean es de $12^{\circ}$. La cara frontal del panel es una pantalla de un blanco mate uniforme. A través de esta pantalla, el sujeto ve aparecer los flashes. El experimento consta de tres series. Se utilizan, en cada una de las series, el mismo número de elementos de señalización, a saber 4 bombillas positivas y 4 bombillas "inhibitorias" o negativas. Lo único que cambia son las posiciones respectivas de los elementos positivos y negativos. (Figura 1).

Figura 1

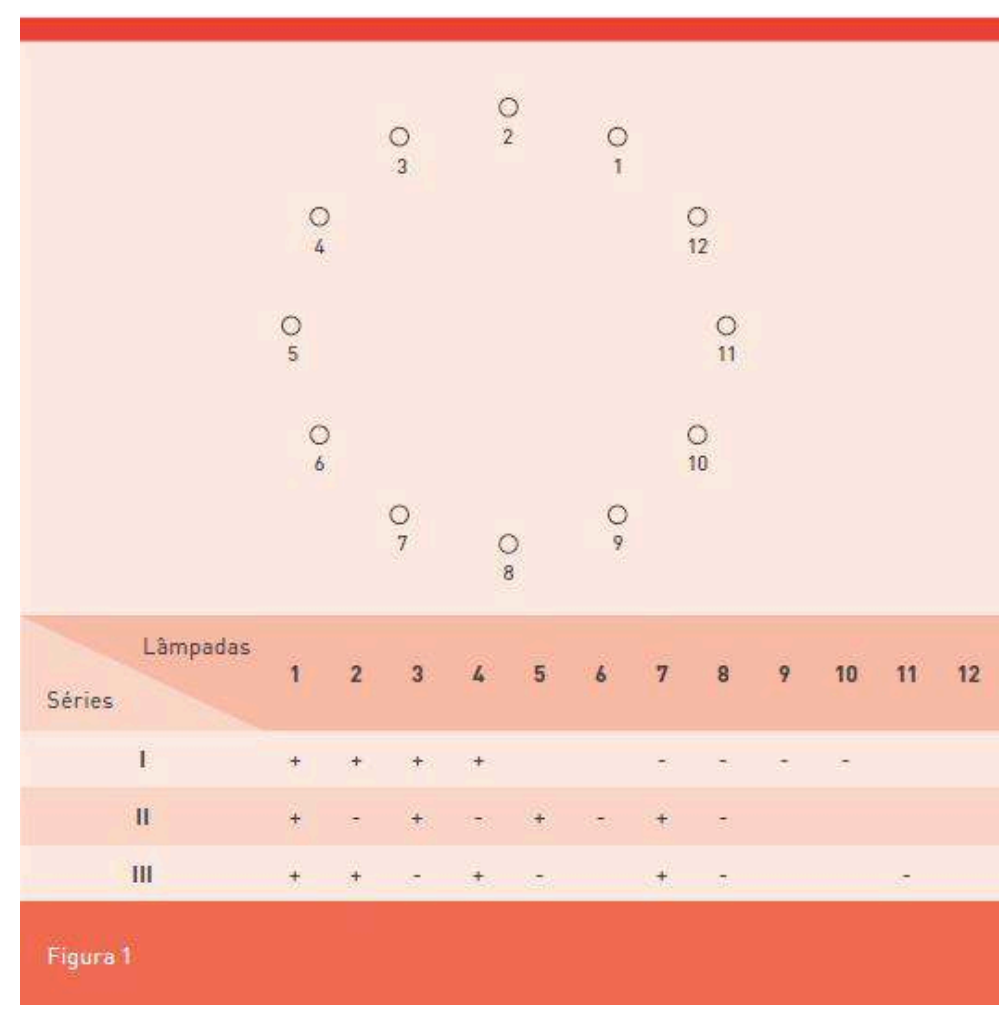

12 Antes del comienzo de cada serie de experimentos, el experimentador muestra sucesivamente los ocho elementos de señalización de la serie iluminándolos uno por uno e indicando aquellos que, en esta ocasión, serán positivos y aquellos que serán negativos. El experimento comienza en cuanto el sujeto ha logrado retener la disposición de los elementos de señalización. El sujeto mantiene su dedo índice apoyado sobre una tecla del pupitre y la presiona cuando alguno de los cuatro elementos positivos se ilumina. El período de latencia en la reacción del sujeto queda registrado con la ayuda de un cronómetro a la milésima de segundo. Las señales positivas e inhibitorias (negativas) se suceden con una probabilidad indistinta y siguiendo el mismo programa para todos los sujetos, el cual es establecido siguiendo la ley de distribución aleatoria. Además, los intervalos de tiempo entre dos flashes sucesivos son de aproximadamente 7 segundos. Luego de cada serie de experimentos, el sujeto hace las observaciones pertinentes (verbales y gráficas) respecto de su desempeño. El 
experimento se considera finalizado cuando el sujeto ha tenido, por cada serie, 20 reacciones exactas en las señales positivas (no cuentan las reacciones especialmente lentas). Como criterios de dificultad, se toman: $1^{\circ}$ el tiempo de reacción promedio, $2^{\circ}$ la variación de los tiempos de reacción, $3^{\circ}$ el número de errores, $4^{\circ}$ el número de reacciones especialmente lentas.

En estos experimentos participaron veinte sujetos, en su mayoría estudiantes de Ciencias humanas de la Universidad de Moscú.

\section{Resultados de los experimentos}

Los principales resultados aparecen en las siguientes tablas.

Tabla 1 - tiempo de reacción promedio (20 sujetos)

\begin{tabular}{|l|l|l|l|l|}
\hline \multicolumn{2}{|l|}{ En milisegundos } & En \%, en relación con el tiempo de reacción promedio de la primera serie \\
\hline \multicolumn{2}{|l|}{ Series } & & & \\
\hline I & II & III & I & II \\
\hline 44,4 & 111,2 & 90,1 & 100 & 253 \\
\hline
\end{tabular}

Tabla 2 - variación promedio del tiempo de reacción promedio

\begin{tabular}{|l|l|l|}
\hline \multicolumn{2}{|l|}{ Series } \\
\hline I & II & III \\
\hline 23,0 & 40,5 & 33,0 \\
\hline
\end{tabular}

17 Tabla 3 - Reacciones especialmente lentas

\begin{tabular}{|l|l|l|}
\hline \multicolumn{3}{|c|}{ Series } \\
\hline I & II & III \\
\hline 0 & 14 & 10 \\
\hline
\end{tabular}
errores de la primera serie

Series 


\begin{tabular}{|l|l|l|l|l|}
\hline I & II & III & I & II \\
\hline 13 & 169 & 52 & 100 & 1300 \\
\hline
\end{tabular}

\section{Discusión de los resultados} operativa. reaccionar a los flashes. adoptados.

Está claro que en nuestros experimentos los flashes pertenecen a una categoría de señales cuyo contenido queda en evidencia por una confrontación con la imagen

Conforme a nuestra hipótesis, durante la presentación de las señales positivas y negativas al sujeto, y a medida que este toma consciencia de su disposición, se forma una imagen operativa, diferente para cada una de las series de experimentación. Cada uno de los ocho puntos de la pantalla se vuelve, en la imagen, portador de una información, a saber: cómo reaccionar ante estos flashes (es decir, si debe responder a ellos presionando o no la tecla). El conjunto de estos ocho puntos informacionales "funcionando" en la serie, constituye el volumen del contenido informacional de la imagen (su aspecto cuantitativo).

El proceso de confrontación de la información proporcionada por las señales con la información proporcionada por la imagen consiste en:

1. reconocer las posiciones respectivas de los flashes que se suceden, proyectándolas luego sobre los puntos informacionales correspondientes de la imagen;

2. emplear la información que aportan estos puntos, es decir ejecutar la consigna relacionándola cada vez con un punto preciso y teniendo en cuenta la manera adecuada de

Los resultados del experimento han mostrado que la dificultad en el tratamiento de la información no es en absoluto la misma para las distintas series, siguiendo los criterios

4 La variación en la dificultad para las distintas series no puede ser atribuida a una variación en la cantidad de información-señal, por la simple razón de que tanto el número de señales positivas y negativas, la probabilidad de aparición de cada una de ellas como los intervalos entre dos señales sucesivas, son los mismos en las tres series.

5 Tampoco es posible explicar esta variación con la cantidad de información-imagen, ya que el número de puntos informacionales ha permanecido constante a lo largo de todo el experimento $(4+4=8)$ y en consecuencia, la cantidad de información-imagen no sufrió ninguna modificación al pasar de una serie a otra.

Así pues, quedan las diferencias cualitativas. Como ya hemos señalado, cada serie se distinguía por las posiciones respectivas de las bombillas consideradas "positivas" y "negativas". No cabe duda de que la modificación en la disposición de las bombillas, una en relación con la otra, exigía una modificación en el modo de ordenamiento estructural de los puntos informacionales de la imagen. A su vez, la organización estructural de la información-imagen, diferente para cada serie, ha influenciado de diversos modos la eficacia en la resolución de las tareas experimentales.

27 Los informes gráficos y verbales que nos suministraron los sujetos dan la posibilidad de restablecer, en parte, los procesos de estructuración operativa de la imagen. 
$1^{\circ}$ Una de las dos formas esenciales de estructuración consiste en la integración y diferenciación de la información-imagen a partir de la delimitación y observación de las estructuras semánticas parciales o bloques informacionales. De hecho, se trata de un procedimiento de reagrupación semántica explicado por A. Smirnov $(/ 4 /)$ para los procesos de memorización y que hoy día es ampliamente estudiado como técnica de information chunking. Se sabe que J. Miller (/11/) aplicó este procedimiento para la memorización de las sílabas, M. Mayzner y R. Gabriel (/10/) para la memorización de los números, B. Cohen $(/ 7 /)$ para la memorización de las familias de palabras. En nuestros experimentos, esta reagrupación se dio en el establecimiento de las relaciones espaciales entre los puntos informacionales.

En algunos casos, estas relaciones eran simbolizadas por líneas imaginarias que unían los puntos informacionales y se integraban en estructuras visuales imaginarias (Figura 2).

Entre los informes de los sujetos, las siguientes citas evidencian los mismos fenómenos. Sujeto $3,2^{a}$ serie: "Arriba hay un trapecio, luego una bombilla positiva y una negativa. Abajo, un semicírculo." Sujeto $5,2^{a}$ serie: "Me equivoqué debido al cambio de un triángulo a un rombo. En la primera serie, durante mucho tiempo solo aparecían triángulos, así que dejé de prestarles atención a los rombos y buscaba solo los triángulos. En la segunda serie, al principio aparecían solo rombos pero después aparecieron los triángulos."

Figura 2. Puesta en evidencia de las estructuras semánticas parciales. Insertar imagen

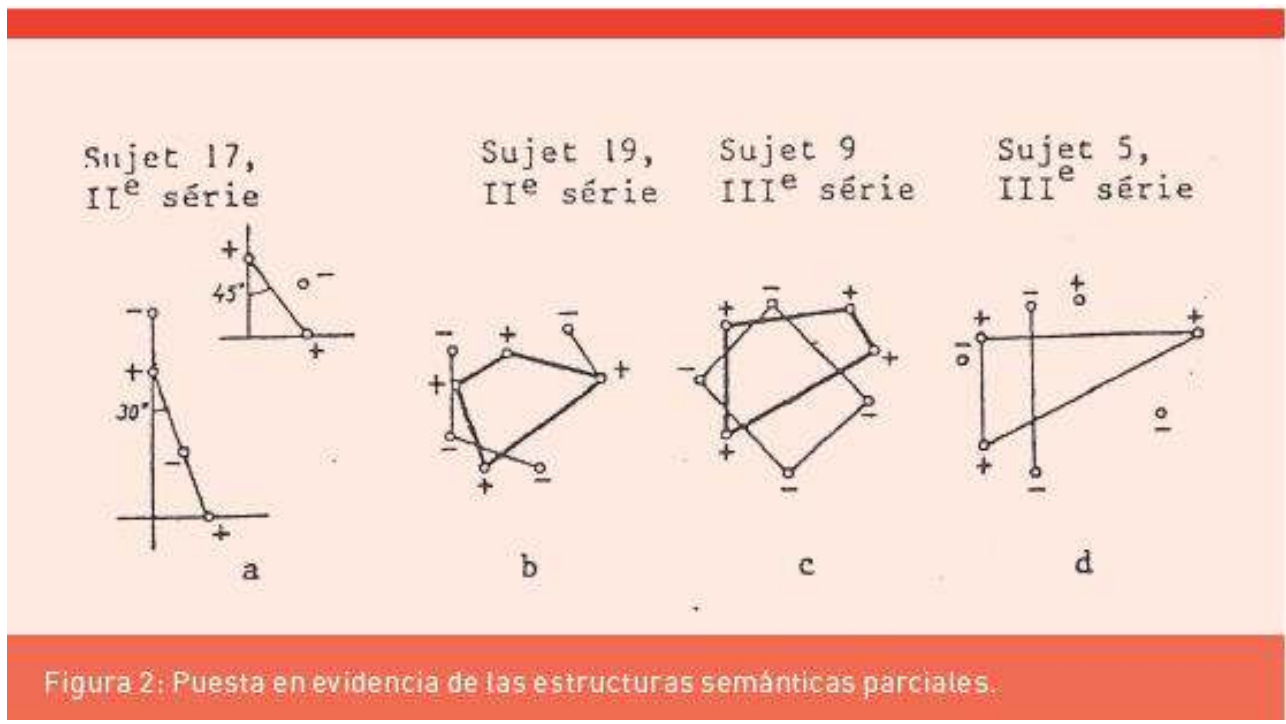

31 En otros casos, las relaciones espaciales parciales fueron establecidas a través del desplazamiento, en la imagen, de ciertos puntos informacionales en relación con los demás, formando de esta manera una agrupación espacial de los puntos informacionales (Figura 3). 
Figura 3. Agrupación de los puntos informacionales por desplazamiento.

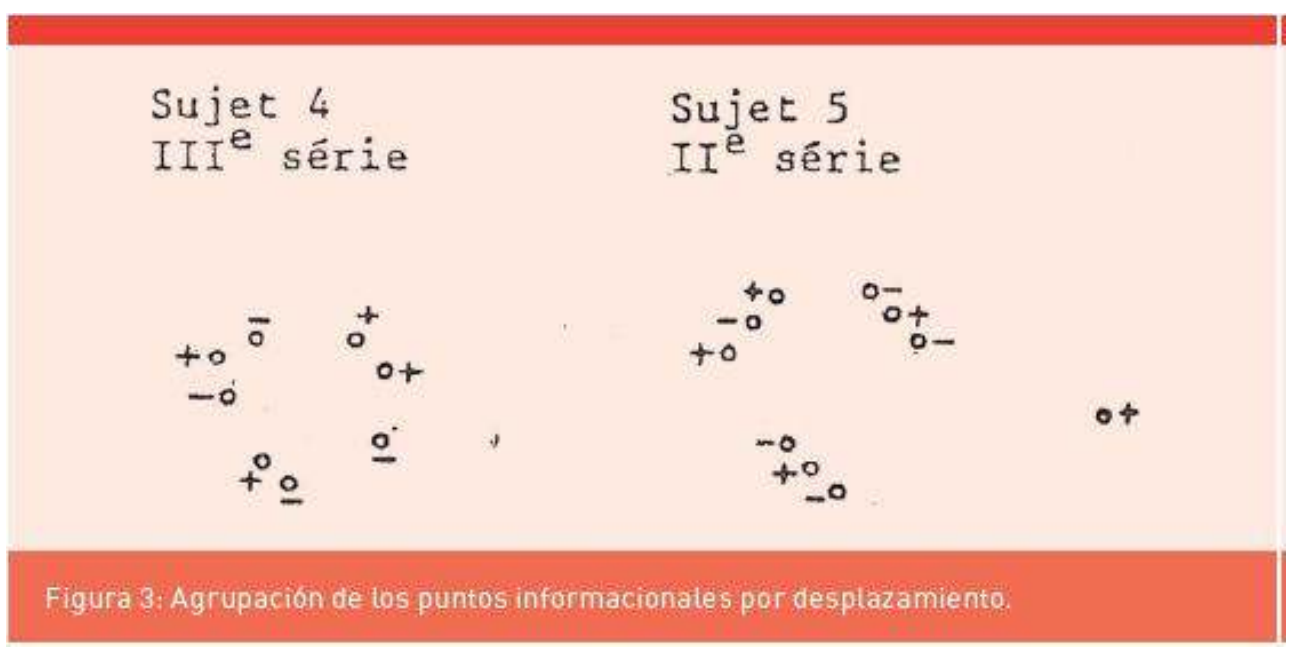

Este fenómeno de desplazamiento recuerda la transformación libre de los engramas en la psicología de la Gestalt, con la diferencia esencial, no obstante, de que en nuestros experimentos el desplazamiento no se veía afectado de ningún modo a la ley de pregnancia de la forma y que este desplazamiento no era gráfico sino semántico.

Los informes gráficos de los sujetos muestran que los bloques informacionales obtenidos a través del desplazamiento y la agrupación en la imagen pueden ser tanto homogéneos (cf. Figura 5) como heterogéneos, es decir que cuentan con una estructura informacional diferenciada que les pertenece.

4 En nuestros experimentos, los elementos constituyentes de estos bloques heterogéneos son las agrupaciones ordenadas de dos o más puntos informacionales positivos y negativos (Figura 3).

En las imágenes operativas correspondientes a las distintas series, debido a que los mismos puntos informacionales aparecieron en distintas ubicaciones (a causa de su reagrupación semántica), el efecto de desplazamiento provocó en algunos sujetos una curiosa ilusión de movimiento de las bombillas sobre la pantalla:

“Todas las bombillas se movían, menos una." (Sujeto 19).

"El marco de la pantalla se mueve. No tiene límites concretos. (El experimentador invita al sujeto a que se persuada de que el marco está fijo.) Probablemente tuve esa impresión porque las bombillas se movían." (Sujeto 17).

$2^{\circ}$ La segunda forma de estructuración que observamos en nuestros experimentos es la localización de los puntos informacionales a través del uso de marcas o ejes de referencia establecidos mentalmente en el espacio (Figura 4). 


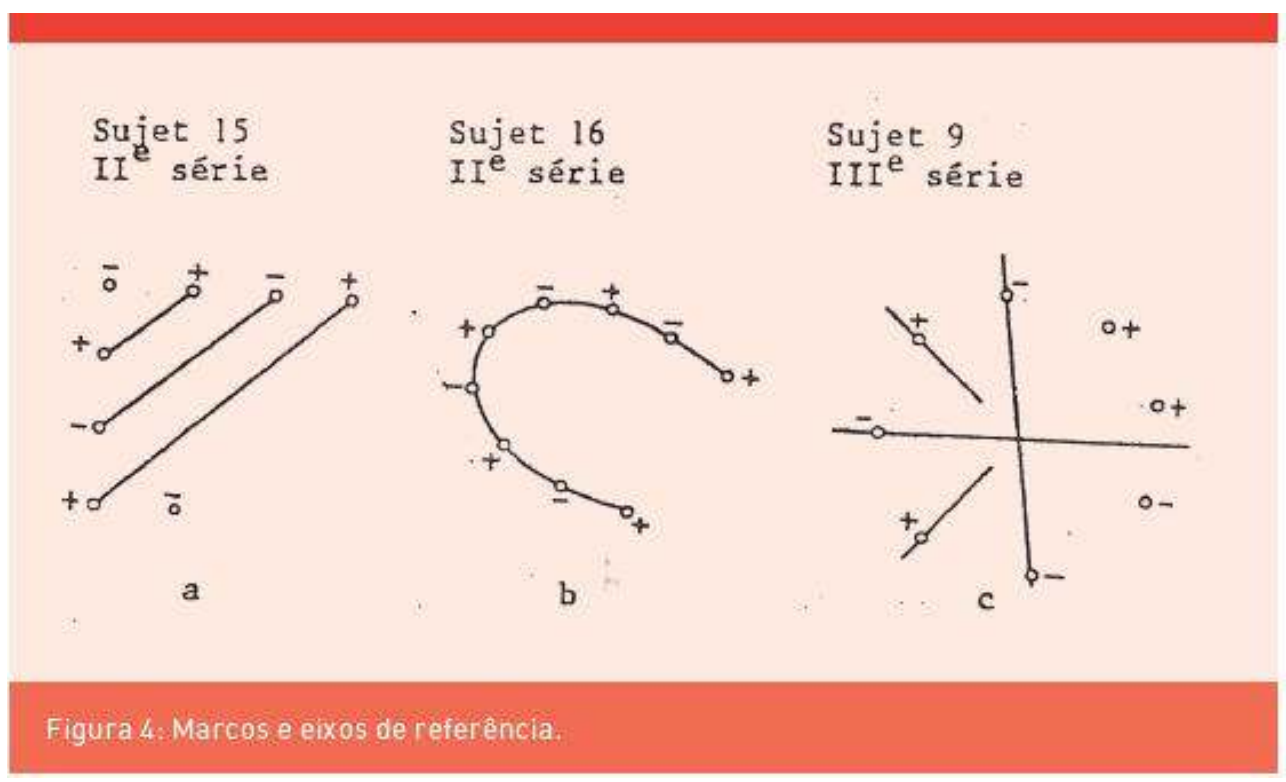

Las marcas no aparecían solamente en los puntos informacionales que los sujetos fueron señalando a lo largo de esta localización, sino también en el marco de la pantalla y sus ángulos. Uno de los sujetos se orientaba utilizando la posición de algunos objetos del laboratorio que se hallaban dentro de su campo visual a modo de referencia.

Veamos un fragmento del informe de este sujeto: "La primera bombilla (positiva) se hallaba al borde de la cortina; la segunda (negativa), en medio del contramarco blanco de la ventana; la tercera (positiva), sobre el muro; la cuarta (negativa), sobre la bisectriz del ángulo superior izquierdo de la pantalla; la quinta (positiva) estaba aislada; solo recuerdo que estaba un poquito más arriba que la siguiente, negativa; la sexta (negativa) estaba más baja que la quinta; la séptima (positiva), justo sobre la bisectriz del ángulo inferior izquierdo de la pantalla; la octava (negativa), a la izquierda de la bisectriz, no sobre ella sino al lado". (Sujeto $13,2^{\mathrm{a}}$ serie).

Consideramos que los procedimientos de estructuración operativa señalados bastan para explicar las diferencias de dificultad entre las distintas series de experimentos.

Así pues, la ventaja de la primera serie por sobre la tercera, y sobre todo por sobre la segunda, consiste sin duda en que la disposición simétrica y polarizada de los puntos informacionales en esta serie constituía un factor extremadamente favorable para el discernimiento entre dos estructuras semánticas parciales, homogéneas y opuestas. 


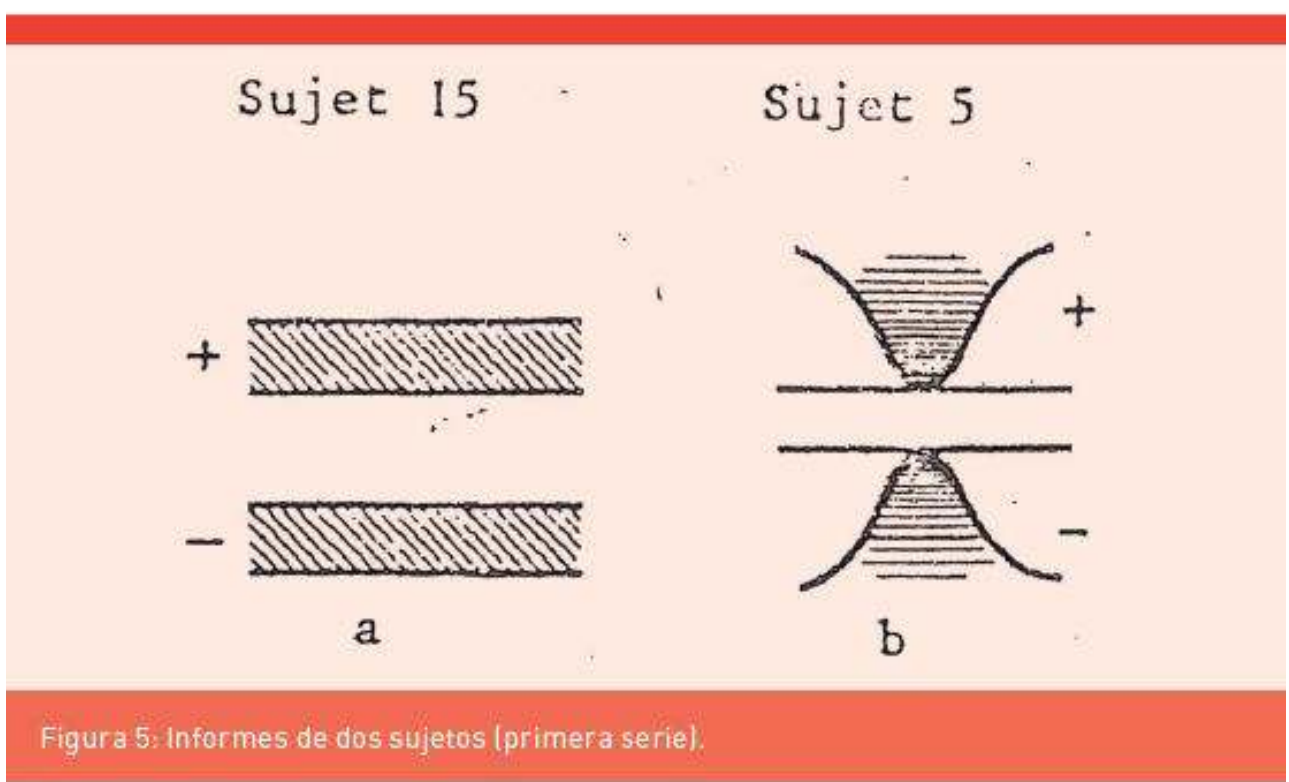

De hecho, el objeto en sí mismo (la pantalla y las bombillas) estaba, en esta serie, tan bien organizado desde el punto de vista operativo que la necesidad de una estructuración suplementaria de la imagen se volvía inútil. Para esta serie, lo único necesario era elaborar una imagen operativa extremadamente simple y lacónica, que contuviera la siguiente información: todos los elementos de señalización positivos se hallan "arriba" y todos los negativos, "abajo" (Figura 5).

En estas condiciones, incluso la indicación referente a la cantidad total de elementos positivos y negativos, y sobre todo, la indicación referente a sus respectivas posiciones sobre la pantalla se volvía superflua, y por más raro que parezca, la mayoría de los sujetos no tomaban estas indicaciones en consideración. Como hemos visto, antes de comenzar el experimento, se les informaba a los sujetos que en cada serie aparecerían ocho señales $(4+4=8)$ y que, tanto para la primera serie como para las demás, primero se les mostrarían las ocho señales sobre la pantalla. Sin embargo, en el transcurso del experimento los sujetos olvidaron la cantidad de señales (Figura 6). 


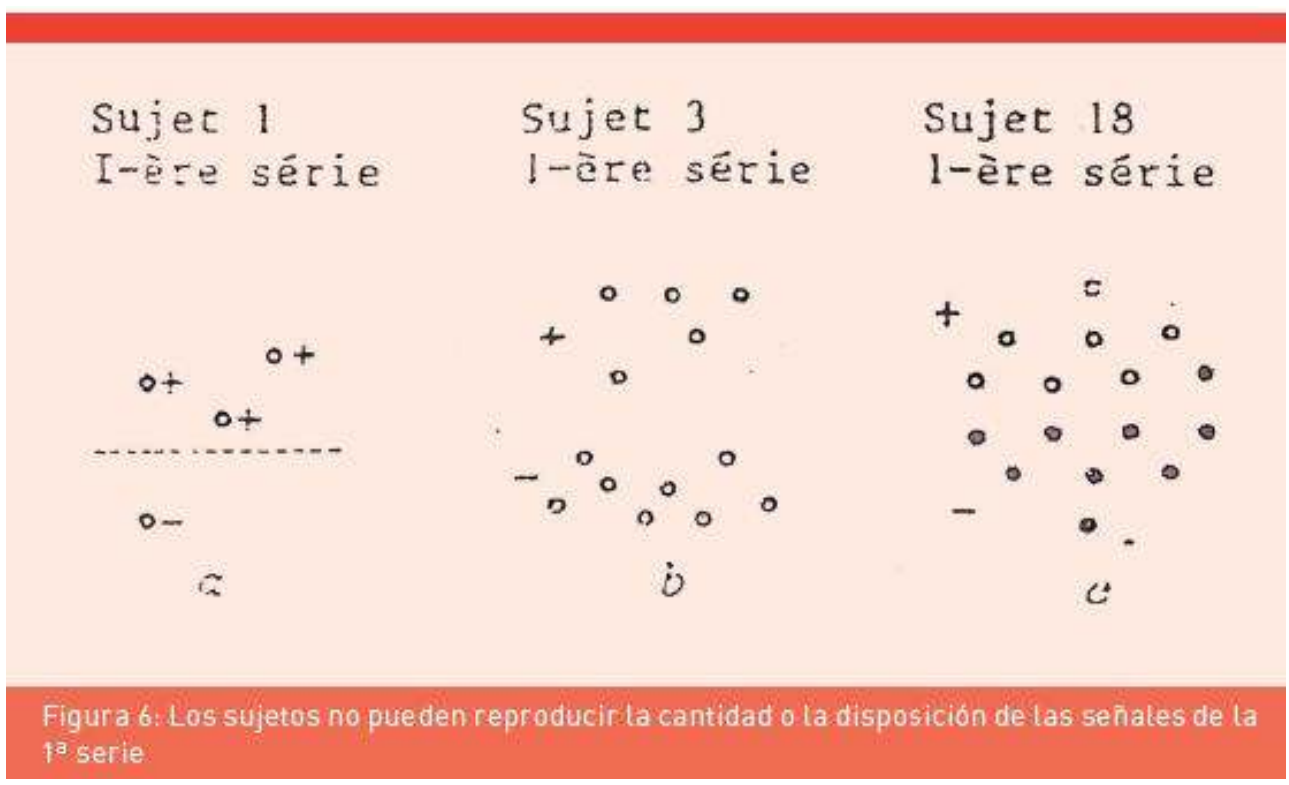

En algunos casos, cuando se les pedía que reprodujeran todos los elementos de la primera serie o que indicaran su cantidad, los sujetos se quejaron argumentando que el experimentador debería haberles aclarado con anticipación aquello que luego tendrían que recordar.

En la segunda serie, la más difícil, todos los sujetos captaron fácilmente el principio elemental de alternancia entre elementos positivos y negativos. Sin embargo, las respuestas de los sujetos muestran que no les fue fácil representar este principio en forma de estructuras espaciales parciales claramente diferenciadas, es decir que no les fue fácil formar una imagen operativa eficaz; esto evidentemente desembocó en resultados muy inferiores en su trabajo.

En la siguiente serie, la tercera, la disposición de los elementos de señalización favorecía en gran medida la conexión de los puntos informacionales en bloques semánticos, aun si el principio de sucesión circular de los elementos positivos y negativos fue más complicado en esta serie.

En este experimento, lo que nos interesaba inmediatamente, era una clase muy específica de imágenes operativas, a saber las imágenes que intervienen en la captura del contenido informacional de las señales. Sin embargo, es posible que los principios de la estructuración de imágenes operativas mencionados tengan un mayor alcance y sirvan para alguna aplicación práctica importante. Intentemos probarlo con un ejemplo. Se conoce el rol que juegan, en las condiciones del control remoto, las representaciones esquemáticas de los objetos controlados sobre los paneles de información. Por otro lado, a menudo hemos llamado la atención sobre el hecho de que el esquema mnemónico (sinóptico) podía cumplir su función solamente en el caso de ser isomorfo tanto con relación al objeto controlado como a la imagen de este objeto, imagen que le permite al operador tratar la información que le llega del objeto. Asimismo, hemos subrayado que el trabajo realizado con un esquema sinóptico bien constituido era, para el operador, un método eficaz para formarse la imagen más adecuada para la tarea de control que debía cumplir (/2/). 

Comparemos la variante "psicológica" que establecimos del cuadro sinóptico de circuito de aceite de una central termoeléctrica $(/ 3 /)$ con el cuadro sinóptico "tecnológico" de este mismo circuito (Figuras 7 y 8 ).

Figura 7. Variante "psicológica"

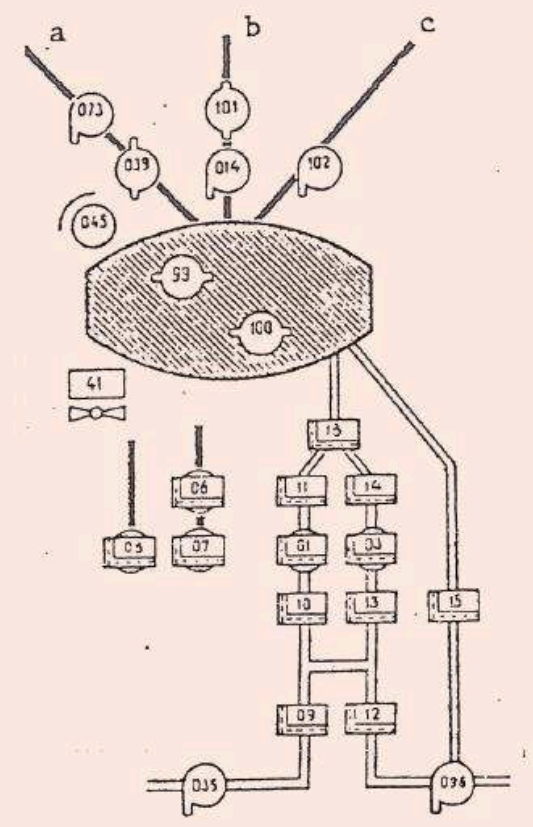

Figura 7.Variante "psicológica" 


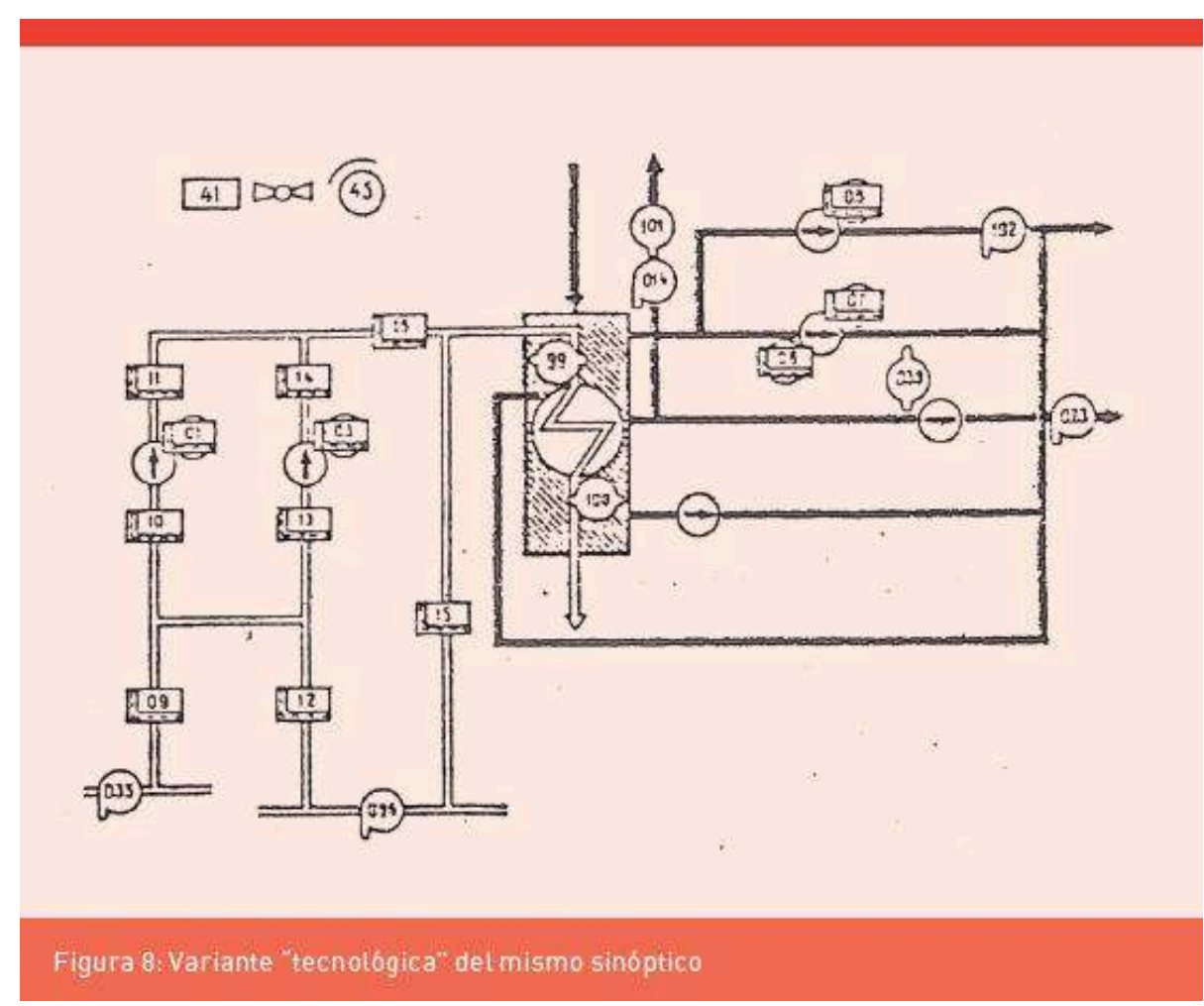

Lo que distingue fundamentalmente a nuestro cuadro sinóptico de la variante "tecnológica" es que el primero está basado en el principio de integración y diferenciación de la información-imagen a través de la puesta en evidencia de estructuras semánticas parciales, que observamos al momento de la formación de la imagen operativa en nuestros sujetos. En este caso concreto de esquema sinóptico, este principio encontró su expresión en:

a. una delimitación clara de la zona de señalización (instrumentos indicadores 073, 039, 045, $101,014,102,99,100$ ) y de la zona de control (válvulas 09, 10, 11, 12, 13, 14, 15, 18 y motobombas 08, 06, 07, 01, 03);

b. el enlace estructural de las salidas ("direcciones") del grupo electrógeno conectadas a las fuentes de información correspondientes (tres líneas en la parte superior de nuestro esquema);

c. el aislamiento estructural, al interior de la zona de control, y la organización en una línea inmediatamente visible, de las bombas de aceite y de agua que son los principales mecanismos de acción en la dinámica de los fluidos tecnológicos (08, 07, 01, 03);

d. la atribución de una forma característica e impresionante a la representación del grupo electrógeno en su conjunto, que favorece la localización operativa de la información que se relaciona en su interior por sobre el cuadro sinóptico general de la central, extremadamente complicado y cargado.

48 A lo largo de un experimento comparativo sobre la eficacia de las dos variantes de sinóptico, efectuado sobre el modelo dinámico del grupo electrógeno, el tiempo promedio para las operaciones de producción se vio reducido a menos del $28,5 \%$, gracias a nuestro esquema, y la cantidad total de los errores cometidos por los sujetos-"operadores" se vio reducida al 5,5\% (/2/, /47/). 


\section{Conclusiones}

Este estudio estuvo basado en el esquema de principio ya utilizado para establecer y verificar la ley de Hick. Para todas las series de experimentos, se mantuvo: a) la complejidad en la elección de reacción (alternativa: presionar/no presionar la tecla); b) la cantidad de elementos de señalización $(4+4=8)$.

Los experimentos han aportado los siguientes resultados:

$1^{\circ}$ Se ha comprobado que la dificultad del trabajo presentó grandes diferencias en las distintas series, al contrario de lo que se habría podido suponer a partir de los planteos de Hick (/8/), R. Hyman (/9/), T. N. Ouchakova (/6/) y otros autores.

$2^{\circ}$ Se ha puesto en evidencia que el rol de la estructura de la imagen operativa para la captura del contenido informacional de la señal.

$3^{\circ}$ Se han hallado algunas formas de estructuración operativa para la formación de la imagen operativa.

$4^{\circ}$ Se ha demostrado, gracias al análisis comparado de dos esquemas sinópticos de un mismo objeto, la posibilidad de una interpretación más extendida, y de una utilización práctica de los resultados de la investigación.

\section{BIBLIOGRAFÍA}

Ochanine D. Le système psychologique sous-tendant l'action sur l'objet.

Problèmes de psychologie industrielle, III, Moscú, 1968.

Ochanine D. L'image opérative d'un objet commandé dans les systèmes "homme-automate". XVIII Congrès international de psychologie. Symposium 27. Problèmes psychologiques des systèmes “hommes-machines”. Moscú, 1966.

Ochanine D. Psychologie industrielle et ergonomie. Encyclopédie soviétique des techniques modernes. Automatisation de la production et électronique industrielle., t.3.

Smirnov A. Les processus mentaux de la mémorisation. Bulletin de l'Académie des Sciences pédagogiques de la R.S.F.S.R. 1, 1945.

Tioukhtine V. De la nature de l'image. Moscú, 1963.

Ouchakova T. Interpretation de la loi de Hick. Questions de psychologiem №6, 1964.

Cohen B. Investigation of recording in free recall. Journal of Experimental Psychology. 1963, 65.

Hick W. On the rate of gain of information. Quart. Journal of Experimental Psychology. 1952, 또 №1.

Hyman R. Stimulus information as a determinant of reaction time. Journal of Experimental Psychology. 1963, №45.

Mayzner M, Gabriel R. Information "chunkin" and short-terme retention. Journal of Psychology. $1963, \underline{56}$. 
Miller, G. Human memory and the storage of information. IRE Transactions on Information Theory. 1956, V. IT-2, №3. 